\title{
Effectiveness of Taping for the Short-Term Treatment of Pain and Walking Speed in Patients with Plantar Fasciitis
}

\author{
Mira Muhammad,* Angela BM Tulaar,* Rosiana Pradanasari,* Saptawati Bardosono** \\ * Department of Physical Medicine and Rehabilitation, Cipto Mangunkusumo Hospital - \\ Faculty of Medicine, University of Indonesia, Jakarta, Indonesia \\ ** Department of Nutrition Science, Cipto Mangunkusumo Hospital - Faculty of Medicine, \\ University of Indonesia, Jakarta, Indonesia
}

\begin{abstract}
Plantar fasciitis causes pain in the heel and medial arch of the foot can interfere daily activities. Taping the plantar fasciitis will reduce pain by reducing strain on the plantar fascia during standing and ambulation.

Objective: to see the effect of taping on pain and walking speed.

Methods: fifteen subjects received taping and ultrasound diathermy therapy for one week. Fifteen other subjects received ultrasound therapy alone. Pain measured by Visual Analogue Scale (VAS) and the walking speed is measured in meters / sec.
\end{abstract}

Results: VAS score started to differ significantly on the first day after treatment $(p=0.008)$ and continues until the last day of evaluation. On the first day, the VAS score changes differs significantly $(p=0.002)$. But in the evaluation of the days, the change of VAS scores were not significantly different. VAS score changes on the seventh day compared to the initial evaluation found significant $(p<0.001)$. With multivariate analysis of repeated measurements, VAS scores in each group decreased significantly $(\mathrm{p}<0.001)$, but the decrease in VAS score taping group were significantly better compared with non-taping group $(p=0.004)$.

Conclusion: combination of taping and ultrasound diathermy for people with plantar fasciitis can be used as a modality to reduce pain more quickly.

Keywords: : plantar fasciitis, taping, ultrasound diathermy, visual analog scale, walking speed.

Received in March 2016 and accepted for publication in April 2016.

\section{Correspondence Details:}

Mira

Jl. Prada I LR. Seulanga No. 22

Kp. Pineung, Banda Aceh

Phone: 08126906305

Email: mira.muhammad.mm@gmail.com

\section{INTRODUCTION}

\section{Background}

Pain under the heel is most often caused by plantar fasciitis with or without calcaneal spur. ${ }^{1}$ Plantar fasciitis is an overuse injury due to a recurrent tear at the origin of the plantar fascia on the tuberosity of the calcaneus, which is in the distal part of the medial pain and heel. ${ }^{2}$ The tenderness of the heel that spread to the rest of the foot is 
the most common. ${ }^{1}$ Plantar fasciitis is a common foot disorders in polyclinic. ${ }^{3}$ In developed countries, plantar fasciitis was found to be $11 \%$ - $15 \%$ of all complaints in the legs in adults and $10 \%$ in athletic runner. This number increased in the age group 40-60 years old and more on a younger athletic runner. ${ }^{4}$ Asmaun Najamuddin conducted in 2003 in the Department of Medical Rehabilitation RSCM in 67 patients with plantar fasciitis found that the youngest 34 years old and the oldest 60 years old. When grouped ages 30 39 years old is $17 \%$, aged $40-49$ years old is $40 \%$ and aged 50-60 years old is $43 \%$.

Plantar fasciitis causes pain in the heel and medial arch of the foot plantar surface can interfere daily activities. ${ }^{6}$ Its management can be conservative or surgical. A systematic review has examined a variety of conservative treatment for plantar fasciitis and concluded that the best therapy is the principle of lowcost and low-risk. ${ }^{7}$ Foot orthoses is one of therapy for plantar fasciitis, but it takes time for made to fit the patient's feet. So it needs a temporary therapy to help patients eliminate foot pain while making foot orthoses. The therapy is taping at the foot of patients with plantar fasciitis. Taping will reduce pain by reducing strain on the plantar fascia during standing and ambulation. ${ }^{8}$

This recent days, using taping as a temporary therapy in reducing pain in people with plantar fasciitis is not a standard treatment in Indonesia yet. While the pain will make sufferers difficult to perform daily activities and this will impact on the psychological, social and economic. This enables researchers to examine the effectiveness of taping as the addition of ultrasound modality therapy in plantar fasciitis. The results are expected to provide benefits for pain management in patients with plantar fasciitis.

\section{METHODS}

This study used a parallel randomized clinical trials to see the effectiveness of plantar taping as short-term therapy for patients with plantar fasciitis. Research was held at Medical Rehabilitation Polyclinic, Department of Medical Rehabilitation RSUPN dr. Cipto Mangunkusumo Jakarta. Data collection was July 2010 until July 2011.

Inclusion criteria are subject with plantar fasciitis acute / subacute, men and women aged 30-60 years old, body mass index (BMI) less than 25, foot pain on one condition: when you wake up in the morning, when standing and when walking with VAS greater than or equal to 5, the pain only on one foot (one-free foot pain), not currently receive treatment for plantar fasciitis, able to walk without a walker, willing to complete the study by signing informed consent.

Exclusion criteria are wounds/injuries to feet, abnormalities of the joints in the lower extremities, history of allergy of tape, impaired cardiorespiratory function that limits the ability of walking, and neuromuscular disease or cognitive impairment.

After signing informed consent, subjects were divided to random permutations of 6 blocks into 2 groups: group using taping + USD and the USD group only. The assessment of function of the foot was carried out 4 times with walking speed in 15 meters. The first assessment carried out on the first day without taping, the second was performed on the third day of the taping, the third was on the fifth day and the fourth was on the seventh day of taping. Taping is installed after the first walking test by the researcher. Taping will be replaced on subsequent visits. VAS assessment is done every day through daily record when the subject wake up in the morning and by phone by researcher. The use of taping was 1 week. 
USD was on the first day (before taping, Visit I), the third day (Visit II), fifth day (Visit III) and seventh day (Visit IV).

The data obtained are recorded, coded then inserted into the worksheet using the SPSS 11.5 then analyzed and interpreted.

\section{RESULTS}

\section{Characteristics of Subjects}

The samples were 30 patients, 26 women and 4 men. The characteristics of the subjects are in Table 1, both groups had similar characteristics (homogeneous).

Table 1. Characteristics of Subjects

\begin{tabular}{lccc}
\hline \multicolumn{1}{c}{ Characteristic } & Taping Group & Non Taping Group & p Value \\
\hline Age & $43.33 \pm 10.39^{*}$ & $52.00(36-59) \#$ & 0.092 \\
Gender, n(\%) & $2(13.3)$ & $2(13.3)$ & \\
$\quad$ Male & $13(86.7)$ & 1.000 & 1.000 \\
Female & $24.14(19.82-24.97)$ & $22.86(22.07-24.65)$ & 0.418 \\
Body mass index & & & \\
Education, n(\%) & $2(13.3)$ & $4(26,7)$ & 0.651 \\
Until 9 y.o & $13(86.7)$ & $11(73.3)$ & \\
Over 9 y.o & & & \\
Side of foot, $\mathrm{n}(\%)$ & $6(40.0)$ & $8(53.3)$ & 0.464 \\
Right & $9(60.0)$ & $7(46.7)$ & \\
Left & & &
\end{tabular}

*, mean $\pm \mathrm{SD} ; \#$, median (minimum-maximum); y.o, years old

\section{VAS Scores Before and After Treatment}

The comparison of VAS scores at first steps after waking up in the two groups shown in Table 2.

Table 2. VAS Scores Before and After Treatment

\begin{tabular}{cccc}
\hline VAS Score & Taping Group & Non Taping Group & p Value \\
\hline VAS (initial) & $6.67 \pm 1.047^{*}$ & $6.67 \pm 1.047^{*}$ & $1.000^{1}$ \\
VAS I & $5.00(3-7) \#$ & $6.00(4-8) \#$ & $0.008^{2}$ \\
VAS II & $5.00(3-7)$ & $6.00(4-8)$ & 0.010 \\
VAS III & $4.07 \pm 1.438$ & $5.53 \pm 0.915$ & 0.002 \\
VAS IV & $4.00(2-7)$ & $6.00(3-6)$ & 0.04 \\
VAS V & $3.00(1-6)$ & $5.00(3-6)$ & 0.001 \\
VAS VI & $3.00(1-5)$ & $5.00(3-6)$ & $<0.001$ \\
VAS VII & $2.60 \pm 1.404$ & $4.60 \pm 0.910$ & $<0.001$
\end{tabular}

*, mean $\pm \mathrm{SD}$; \#, median (minimum-maximum); ${ }^{1}$ unpaired T-test; ${ }^{2}$ Mann-Whitney 


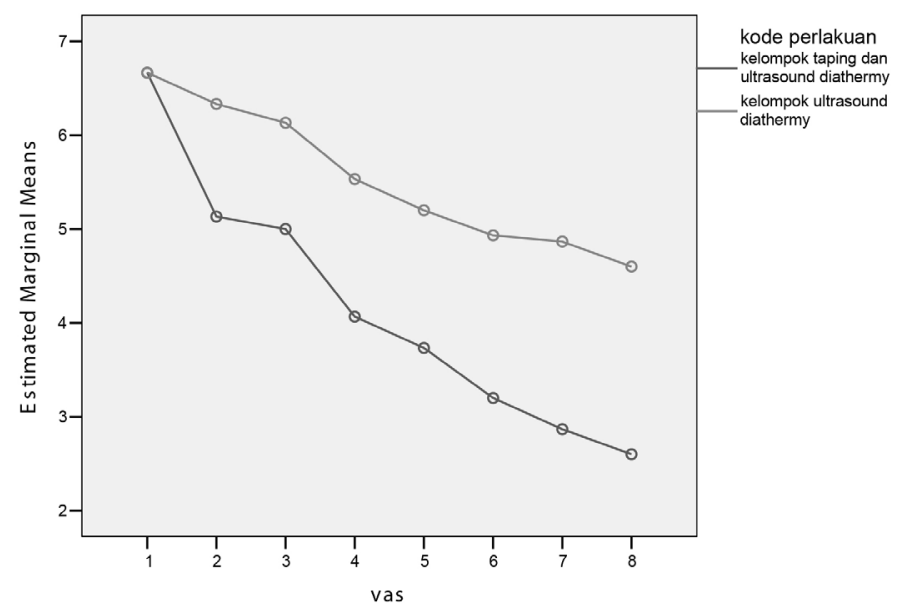

Figure 1. VAS Score Comparison Chart at First Steps after Waking Up

By using advanced analysis, the multivariate analysis of repeated measurements, VAS scores in each group decreased significantly ( $p$ $<0.001$ ), but the decrease in taping group were significantly better compared with non-taping group $(\mathrm{p}=0.004)$ as shown in Figure 1.

Walking Speed Before and After Treatment Comparison of walking speed in both groups shown in Table 4.

Table 3. Walking Speed Before and After Treatment

\begin{tabular}{cccc}
\hline Walking Speed & $\begin{array}{c}\text { Taping Group } \\
\text { meter/second }\end{array}$ & $\begin{array}{c}\text { Non Taping Group } \\
\text { meter/second }\end{array}$ & p Value* \\
\hline Visit I & $1.00(0.75-1.25)$ & $0.88(0.68-0.93)$ & 0.003 \\
Visit II & $1.25(0.75-1.36)$ & $0.93(0.78-1.00)$ & 0.004 \\
Visit III & $1.25(0.78-1.50)$ & $1.00(0.78-1.25)$ & 0.001 \\
Visit IV & $1.36(0.83-1.50)$ & $1.00(0.71-1.25)$ & 0.001 \\
\hline
\end{tabular}

* Uji Mann-Whitney

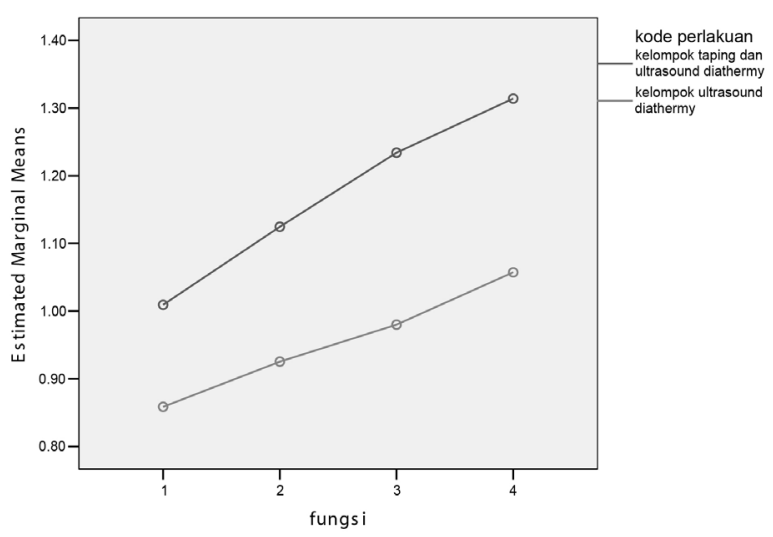

Figure 2. Walking Speed Comparison Chart 
By using advanced analysis, the multivariate analysis of repeated measurements, walking speed in each group increased significantly ( $p$ $<0.001$ ). But the increasing in walking speed between the two groups was not significant $(\mathrm{p}=$ 0.233 ) as shown in Figure 2.

\section{DISCUSSION}

\section{Characteristics of Research Subjects}

The samples were 30 in accordance with the criteria of the study. Both groups have the same characteristic (homogeneous). Women more than men in both groups (taping and non-taping group) of 26 women and 4 men. Najamuddin's research in 2003, and Sjarqiah's in 2007 also showed a sample of women more than men .,9

Age of the sample in this study between 4352 years. This is in accordance with Salam et al who examined unilateral plantar fasciitis and got sample between 40-60 years old by randomization in musculoskeletal therapy clinic. $^{10}$

\section{VAS Scores Before and After Treatment}

This study assessed the first step pain after waking up with VAS measuring the initial (before treatment) until seven days after treatment. Because pain is subjective, we need a tool to measure the intensity of pain. VAS is a tool that can be used to measure the intensity of sensations or feelings, such as pain experienced by someone. ${ }^{11}$

Comparison of VAS scores at the first step in the morning in the two groups, showed a significant difference. VAS scores were significantly different from the first day after treatment $(\mathrm{p}$ $=0.008)$ and continues until the last day of the evaluation. By using the Mann-Whitney test, changes in VAS scores on the seventh day compared to the initial was significant ( $p$ $<0.001)$. This suggests that the decrease in VAS score at the first step in the morning in the taping group is greater than the control group.

Radford et al in a study using the Low-Dye taping on plantar heel pain have a slight decrease in pain after the initial step in therapy for a week. ${ }^{8}$ In our study the decrease in VAS score greater, may be associated with the use of a pulsed ultrasound diathermy with nonthermal effects/mechanical effect that helps the healing of soft tissue. Microstreaming effect will result in a high pressure, which can alter cell membrane structure and function, and alter membrane permeability to sodium and calcium ions, they are important in the healing process. ${ }^{12}$

There are some studies that use taping plantar fasciitis and combined with other therapies. Salam et al compared the use of Low-Dye taping with a medial arch support (MAS) in patients with plantar fasciitis. The subjects also received therapeutic ultrasound diathermy and stretching in 9 sessions over 3 weeks. The result got a significant decrease in the value of pain in both groups, but the decline in pain is better on the MAS significantly. ${ }^{10}$ According to Fleet et al, Low-Dye taping is affected by the activity. Strength will decrease as time passes. Within 15 minutes there is a decrease of $15 \%$, within 1 hour by $48 \%$ and within 24 hours by $86 \%$. This shows the rapid loss of mechanical advocate for nearly $50 \%$ in 1 hour. However, this does not happen in the MAS, which seems better able to maintain and control the mechanical correction rearfoot. ${ }^{13}$ MAS foot orthosis which is one of the treatment of plantar fasciitis, but it takes time to fit the patient's feet. While the patient must remain active to perform daily activities. Taping will reduce the pain by reducing strain on the plantar fascia during standing and ambulasi. ${ }^{8}$ 
Greve et al suggest the use of Low-Dye taping for short-term therapy. This is due to decreased patient compliance in long-term use and presence of complications such as skin allergic. ${ }^{14}$ In this study we found no adverse effects from the taping of the subjects.

Hyland et al in his study with the use of calcaneal taping for plantar fasciitis claimed there was a significant decrease in VAS score compared to sham taping and stretching after a follow-up for 1 week. ${ }^{15}$ Landorf et al stated that the use of Low-Dye taping and stretching better than stretching alone, where the VAS values were significantly decreased during the 2 weeks evaluation. ${ }^{16}$ Lynch et al who studied the combination of Low-Dye taping (the first 4 weeks) followed by foot orthoses until the 12th week stating that the therapy resulted in a significant reduction in VAS values during 12 weeks of therapy compared to the evaluation Non Steroid Anti Inflammation Drug (NSAID) alone and heel cup. ${ }^{17}$

Martin et al, in plantar fasciitis study, subjects divided into 3 groups: Low-Dye taping (the first 2 weeks) followed custom orthoses until week-12: Low-Dye taping the first 2 weeks of continued over-the-counter arch support until the 12th weeks ; posterior tension night splint. After a 12-week evaluation found no pain during daily activities significantly between the three groups, but the better value obtained in the first group. And no decrease in the value of the initial step pain significantly between the three groups, but the better value in the third group. ${ }^{18}$

Changes in VAS scores during the treatment in both groups, using Mann-Whitney test, showed a decrease in median of VAS score in the taping group occured on the first day that is equal to 1 , whereas in the non-taping group VAS score decrease 0 , this result seems significant $(\mathrm{p}=$
0.002). Decrease in VAS score in the non-taping is taking place on the third day evaluation. This suggests that the decrease in VAS score after the first step in the morning in taping group occurs faster than the non-taping.

Before this study, no studies have assessed whether the combination therapy and ultrasound diathermy taping produces a faster decrease in VAS than ultrasound diathermy alone. As we know, the use of a pulsed ultrasound diathermy will produce the effect of non thermal/ mechanical effects that will help the healing of soft tissue. Microstreaming effect will result in a high pressure, which can alter cell membrane structure and function, altering membrane permeability, affecting the diffusion process and the formation of protein, which will affect the speed of tissue healing. ${ }^{12,19}$

Crawford et al reported a study of 19 patients with plantar fasciitis which is divided into 2 groups: pulsed ultrasound diathermy 0.5 watt $/ \mathrm{cm} 2$ intensity, frequency of $3 \mathrm{MHz}$ for 8 minutes, $2 \mathrm{x}$ a week for 4 weeks and the sham ultrasound diathermy. There is a decline in the value of pain in both groups, and comparisons between the two groups was not significant. This might be due to small sample size, ${ }^{20}$ or ultrasound diathermy prescribing inadequate.

The use of taping in people with plantar fasciitis is to prevent soft tissue injuries become more severe even to rupture by way of sustaining it and help healing process without pressing the injured tissue structures. ${ }^{21}$ Taping is very useful as an adjunct therapy in conjunction with ultrasound diathermy. Without the use of taping, plantar fascia which is recovering from the effects of ultrasound diathermy will not protected, so the movement of the fascia is not restricted and excessive stretching occurs. This will result in increased pressure on the plantar fascia and tear easily. ${ }^{22}$ 
According to O'Sullivan et al, the use of LowDye taping will reduce rearfoot pronation by limiting the movement of rearfoot. ${ }^{23}$ The Saxelby et al stated that the Low-Dye taping does not reduce foot pronation, but it can reduce pressure on the fascia plantaris. ${ }^{24}$ The power generated during pronation and supination will increase pressure on the plantar fascia. There should be a balance between pronation and supination. Imbalance will cause a dysfunction of the foot. ${ }^{25}$

\section{Walking Speed Before and After Treatment}

Walking speed is an objective assessment of lower limb function in musculoskeletal diseases in which the subject was calculated the speed with comfortable walking speed with a stopwatch. Speed value obtained by dividing the distance by time. Normal average speed is 80 meters/ minute (11.25 meter detik/15). Its validity will be decreased by the influence of others diseases. ${ }^{26-28}$ In this study researchers included the exclusion criteria if there are wounds/injuries to feet, abnormalities/deformities in the joints in the lower extremities, impaired cardiorespiratory, neuromuscular disease or cognitive impairment. All these things will affect the ability to walk.

Comparison of walking speed in both groups was already significant $(\mathrm{p}=0.003)$ at the initial visit (before treatment), which is $1 \mathrm{~m} / \mathrm{s}$ at the taping and $0.8 \mathrm{~m} / \mathrm{s}$ in the non taping. This is probably because the average age in the taping group is 43 years old, younger than the non taping group 52 years old. Walking ability varies influenced by several factors, including age and physical characteristics of height and weight. Of all the measurements of spatial and temporal, walking speed is the best measurement of the ability of walking function. ${ }^{29}$

Changes in walking speed in the two groups differ significantly on the second visit after treatment $(p=0.004)$ and continues until the last day of the evaluation. But the pattern of change in walking speed between the two groups were not differ significantly $(\mathrm{p}=0.086$ ). More clearly, from the multivariate analysis of repeated measurements, walking speed in each group increased significantly ( $p<0.001$ ). But the increase in walking speed between the two groups was not significant $(p=0.233)$. This is because walking speed is not only affected by pain, but there are other factors that influence such as age, gender, level of physical fitness, height, weight and limb abnormalities. ${ }^{29}$

In this study, the number of men and women is the same between the two groups $(p=1.000)$, so this is not a disturbing factor in the measurement of walking speed. Because in theory, there are differences in the value of walking speed in men and women, where women have a slower walking speed, step length is shorter and faster cadence than men. This is because there are differences between male and female anthropometry. ${ }^{29}$

Age also has a homogeneous characteristics in this study ( $p=0.092$ ). Schimpl et al, in a study that assesses the walking parameters using accelerometry found a relationship between age and walking speed where there is a significant difference of 1.2 minutes $(\mathrm{p}<0.001)$ while running as far as $1 \mathrm{~km}$ at age $<30$ years old versus age $>60$ years old in healthy subjects. ${ }^{30}$

This study doesnot discuss the physical fitness and lower limb abnormalities such as flat foot. This is a limitation of the study, because both of these things will affect the speed of walking. Irving et al suggested a relationship between plantar fasciitis and foot pronation. At the time of the foot in a pronated position, the pressure on the plantar fascia increases. His research also found an association between body mass index and plantar fasciitis in which the greater body 
mass index the more likely plantar fasciitis. Increased body mass index increases the vertical pressure under the heel during walking that causes damage to tissue structure. ${ }^{31}$

This study is the first study to use the walking speed at a distance of 15 meters for the measurement of lower limb function in plantar fasciitis objectively. Other studies assessing the increase of function as a therapeutic efficacy. Radford et al evaluated foot function in patients with plantar fasciitis using the Foot Health Status Questionnaire and found no significant differences in mean values before and after the use of Low-Dye taping for 1 week. ${ }^{8}$

Hyland et al evaluated the functional activity of people with plantar fasciitis by using PatientSpecific Functional Scale (PSFS) before and after 1 week of therapy. Therapy is divided into 3 groups: stretching, calcaneal taping and sham taping and found that although not found significant differences in values before and after therapy, but the better value obtained at the calcaneal taping. ${ }^{15}$

\section{CONCLUSION}

The degree of pain in combination of plantar taping and ultrasound diathermy, or ultrasound diathermy alone for people with plantar fasciitis decreases significantly, but the degree of pain reduction in combination of plantar taping and ultrasound diathermy significantly better than the ultrasound diathermy alone.

Walking speed in combination of plantar taping and ultrasound diathermy, or ultrasound diathermy alone for people with plantar fasciitis increases significantly, but the increase in walking speed was not significantly different between the two groups.

\section{REFERENCES}

1. Cailliet R. Foot and ankle pain. Philadelphia: FA Davis Company; 1980.

2. Pasquina PF, Foster LS. Plantar fasciitis. In: Frontera WR, Silver JK, Rizzo TD. Essentials of physical medicine and rehabilitation: musculoskeletal disorders, pain, and rehabilitation. $2^{\text {nd }}$ ed. Canada. Saunders; 2008.

3. Young CC. Plantar fasciitis. Medscape [internet]. 2008 [cited 2009 Apr 20); 1-3. Available from: http://emedicine. medscape.com/article/86143

4. Buchbinder R. Plantar fasciitis. N Engl J Med. 2004; 350: 2159-66.

5. Najamuddin A. Comparing the benefits of iontophoresis using dexamethasone $0.4 \%$ with iontophoresis using a standard gel to reduce pain and inflammation of the plantar fasciitis. Report the results of the study [thesis]. Jakarta: Physical Medicine and Rehabilitation Sciences, University of Indonesia; 2003.

6. Osborne HR, and Allison GT. Treatment of plantar fasciitis by taping and iontophoresis LowDye: short term results of a double blinded, randomized, placebo controlled clinical trial of dexamethasone and acetic acid. Br J Sports Med. 2006; 40: 545-9.

7. Stuber K, Kristmanson K. Conservative therapy for plantar fasciitis: a narrative review of randomized controlled trials. J Can Assoc Chiropr. 2006; 50 (2): 118-32.

8. Radford JA, Landorf KB, Buchbinder R, Cook C. Effectiveness of low-dye taping for the short term treatment of plantar heel pain: a randomized trial. BMC Musculoskeletal Disorders. 2006; 7: 64; 1-7.

9. Sjarqiah U. Influence the use of night splint for foot pain in people with plantar fasciitis. Report the results of the study [thesis]. Jakarta: Physical Medicine and Rehabilitation Sciences, University of Indonesia; 2007. 
10. Salam MSA, Elhafz YNA. Low-dye taping versus medial arch support in managing pain and pain-related disability in Patients with plantar fasciitis. Foot and Ankle Spec. 2011; 4(2):86-91.

11. Visual analog scale. National Cancer Institute. 2007

12. Draper DO, Prentice WE. Therapeutic ultrasound. In: Prentice WE, Quillen WS, Underwood F, editors. Therapeutic modalities in rehabilitation. $3^{\text {rd }}$ ed. NY: McGraw-Hill, 2005.

13. Fleet K, Galen S, Moore C. Duration of strength retention of ankle taping during activities of daily living. Injury. 2009; 40(3):333-6.

14. Greve JMD, Grecco MV, Santos-Silva PR. Comparison of radial shockwave and conventional physiotherapy for treating plantar fasciitis. Clinics 2009; 64(2):97103.

15. Hyland MR, Webber GA, Cohen L. Randomized controlled trial of calcaneal taping, sham taping and plantar fascia stretching for the short-term management of plantar heel pain. J Orthop Sport Phys ther. 2006; 36(6):364-71.

16. Landorf KB, Radford JA, Keenan AM, Redmond AC. Effectiveness of Low-Dye taping for the short-term management of plantar fasciitis. J Am Podiatr Med Assoc. 2005; 95(6):525-30.

17. Lynch DM, Goforth WP, Martin JE, Odom RD, Preece CK, Kotter MW. Conservative treatment of plantar fasciitis. A prospective study. J Am Podiatr Med Assoc. 1998; 88(8):375-80.

18. Martin JE, Hosch JC, Goforth WP, Murff RT, Lynch DM, Odom RD. Mechanical treatment of plantar fasciitis. A prospective study. J Am Podiatr Med Assoc. 2001; 91(2):55-62.

19. PD Hooper. Physical modalities: A primer for chiropractic. Baltimore: Williams \& Wilkins, 1996.
20. Crawford F, Snaith M. How effective is therapeutic ultrasound in the treatment of heel pain? Ann Rheum Dis. 1996; 55(4): 265-7.

21. Macdonald R. Taping techniques: principles and practice. $1^{\text {st }}$ ed. Oxford, Boston: Butterworth-Heinemann Ltd., 1994.

22. Gluckman J. Plantar fasciitis taping. Ezine Articles. , [2007 Jan 7, cited ...... ].

23. O’Sullivan K, Kennedy N, O'Neill E, Mhainin UN. The effect of low-dye taping on rearfoot motion and plantar pressure during the stance phase of gait. BMC Musculoskelet Disord. 2008; 9:111.

24. Saxelby J, Betts RP. Bygrave CJ. LowDye taping on the foot in management of plantar fasciitis. Foot. 1997; 7:205-9.

25. Bolgla LA, Malone TR. Plantar fasciitis and the Windlass mechanism: a biomechanical link to clinical practice. J Athl Train. 2004; 39 (1): 77-82.

26. Hidajati W. Effectiveness of medial patellar taping applications McConnel way to pain and walking speed in people with knee osteoarthritis. Report the results of the study. New York: Physical Medicine and Rehabilitation Sciences, University of Indonesia; 2007.

27. Ancient HB. Influence the use of wedge shoes with arch of the foot pain in rheumatoid arthritis patients with pes planus. Report the results of the study. New York: Physical Medicine and Rehabilitation Sciences, University of Indonesia; 2004.

28. Djuanda M. Influence of quadriceps isometric exercises with resistance to pain and knee function in patients with osteoarthritis of the knee. Report the results of the study. New York: Physical Medicine and Rehabilitation Sciences, University of Indonesia; 2002. 
29. Simoneau GG. Kinesiology of walking. In: Neumann DA. Kinesiology of the musculosceletal system. St. Louis, Missouri: Mosby, 2002.

30. Schimpl M, Moore C, Lederer C, Neuhaus A, et al. Association between walking speed and age in healthy, free-living individuals using mobile accelerometry - a cross-sectional study. Plos one [2011
August 10]....: open access article. Of 2011. Available from: http://journals.plos. org/plosone/article?id=10.1371/journal. pone.0023299

31. Irving DB, Cook JL, Young MA, Menz HB. Obesity and pronated foot type may increase of the risk of chronic plantar heel pain: a matched case control study. BMC Musculoskelet Disord. 2007; 8:41. 